Journal of Animal and Veterinary Advances 11 (10): 1643-1646, 2012

ISSN: $1680-5593$

(C) Medwell Journals, 2012

\title{
A Simple Cultural Method for Detection of Mycoplasma bovis
}

\author{
Nining Hong, Qian De-Xing, Zhang Deng-Xiang and Ran Long-Zhong \\ Guizhou Animal Disease Control Center, 550008 Guiyang, P.R. China
}

\begin{abstract}
Simple method for the detection of Mycoplasma bovis in both liquid and solid cultures was established. Fresh media were easily prepared and dispatched into an eppendorf tube or a Petri dish, a new cultural procedure was followed with the eppendorf tube closed or the Petri dish sealed. Compared to the conventional methods, appropriate inoculating and subculturing operations got easier and a $\mathrm{CO}_{2}$ incubator was not required; moreover, probable contamination by airborne fungi or bacteria could be reduced or eliminated during long-term incubation. Similarly, M. bovis grew normally and could be investigated by Color-Change Units (CCU) enumeration, colony morphology or PCR assay.
\end{abstract}

Key words: Culture, detect, method, Mycoplasma bovis, media, $\mathrm{CO}_{2}$

\section{INTRODUCTION}

Mycoplasma bovis was first isolated in the USA from the milk of a mastitic cow (Hale et al., 1962). During the past decades, it has spread to numerous countries with the global transport of animals and sperm. $M$. bovis is considered one of the most frequent pathogens causing pneumonia, mastitis and arthritis in cattle. Its pathogenic role is often ignored although, several experimental infections have proved it (Gourlay and Houghtan, 1985; Thomas et al., 1986; Rodriguez et al., 1996; Kumar et al., 2012).

Methods used for definitive diagnosis of $M$. bovis infection include culture, fluorescent antibody test, serology and PCR assay. The most commonly used method is detection by culture. This method is time consuming and often problematic because of nonmycoplasmal bacterial overgrowth (Sachse et al., 1993). Moreover, selective media are necessary and inoculated plates must be incubated in $5-10 \% \mathrm{CO}_{2}$ for at least 2 days and should not be considered negative until 7 days have passed (Jasper, 1981). As a result, significant efforts have been made to develop new detection techniques including PCR assays (Ghadersohi et al., 1997; Hotzel et al., 1996; Pinnow et al., 2001; Bahador et al., 2006).

Researchers reported here a simple method for the detection of mycoplasma. Fresh medium was easily prepared and dispatched into eppendorf tubes or Petri dishes; appropriate inoculating and subculturing operations got easier and a $\mathrm{CO}_{2}$ incubator was not required; moreover, contamination by airborne fungi or bacteria could be reduced or eliminated during long incubation following a simple cultural procedure with the eppendorf tube closed or the Petri dish sealed. Similar to the conventional methods, $M$. bovis grew normally and could be investigated by Color-Change Units (CCU) enumeration (Ueno et al., 2008), colony morphology or PCR assay.

\section{MATERIALS AND METHODS}

Culture media and growth conditions: Mycoplasma strain was cultured in modified Hayflick (1965)'s broth containing PPLO broth (Difco) $2.1 \mathrm{~g}$, horse serum (Solarbio) $20 \mathrm{~mL}, 25 \%(\mathrm{w} / \mathrm{v})$ fresh yeast extract $10 \mathrm{~mL}$, glucose $0.2 \mathrm{~g}$, sodium pyruvate $0.4 \mathrm{~g}$, penicillin $20000 \mathrm{IU} \mathrm{mL} \mathrm{L}{ }^{-1}, 1 \%$ Phenol Red $0.2 \mathrm{~mL}$ and deionized water $70 \mathrm{~mL}$. Medium was passed through $0.2 \mu \mathrm{m}$ filters (Acrodisc ${ }^{\circledast}$ Syringe Filter, PALL Life Science) for sterilization and can be stored at $4^{\circ} \mathrm{C}$ for no $>1$ week.

For preparation of fresh yeast extract, $5 \mathrm{~g}$ dry bakers' yeast (Angel Yeast Co., Ltd. China)was crumbled and mixed with $20 \mathrm{~mL}$ deionized water in a $50 \mathrm{~mL}$ baker; the suspension was treated by microwave (Galanz WD900SL23-2I, mild strength, $10 \mathrm{sec}$ for three times with intervals of $30 \mathrm{sec}$ ). After incubation for 3-5 min, the mixture was transferred to $2.0 \mathrm{~mL}$ eppendorf tubes and centrifuged for $10 \mathrm{~min}$ at $12000 \mathrm{rpm}$ (Sigma $2 \mathrm{k} 15$ ) and the supernatant was used as the extract for the preparation of the media.

Mycoplasmas cells were divided into $100 \mu \mathrm{L}$ aliquots and each aliquot was inoculated into $900 \mu \mathrm{L}$ fresh medium in $10 \mathrm{~mL}$ tubes $(10 \times 5)$ and incubated at $37^{\circ} \mathrm{C}$ with $5 \% \mathrm{CO}_{2}$ (Forma Scientific, Water-Jacketed Incubator 3250). In this research, $100 \mu \mathrm{L}$ aliquot of $M$. bovis was tried to inoculate into $200-800 \mu \mathrm{L}$ fresh media in $1.5 \mathrm{~mL}$ eppendorf tubes and incubated at $37^{\circ} \mathrm{C}$ without $5 \% \mathrm{CO}_{2}$.

Corresponding Author: Nining Hong, Guizhou Animal Disease Control Center, 550008 Guiyang, P.R. China 
Table 1: Determination of growth of $M$ bovis in $900 \mu \mathrm{L}$ fresh medium in $10 \mathrm{~mL}$ tube $(10 \times 5)$ using Color-Change Units (CCU)

Time (h)

\begin{tabular}{lllllllllll}
$\mathrm{CCU}$ & 24 & 48 & 72 & 96 & 120 & 144 & 168 & 192 & 216 & 240 \\
\hline $10^{5}$ & - & + & & & & & & & & \\
$10^{4}$ & - & - & + & & & & & & & \\
$10^{3}$ & - & - & - & + & & & & & & \\
$10^{2}$ & - & - & - & & + & & & & & \\
$10^{1}$ & - & - & - & - & - & - & + & & & \\
$10^{0}$ & - & - & - & - & - & - & - & - & - & - \\
\hline
\end{tabular}

For solid culture, agar plates were prepared by addition of purified agar (Oxoid) in modified Hayflick's broth to a final concentration of $1.0 \%(\mathrm{w} / \mathrm{v})$. Serial decimal dilutions of $M$. bovis sample from $10^{-2}$ to $10^{-5}$ were prepared and a $200 \mu \mathrm{L}$ aliquot was plated in duplicate on the culture media. The Petri plates were sealed with Parafilm ${ }^{\circledR} \mathrm{M}$ (Li et al., 2005) and incubated at $37^{\circ} \mathrm{C}$ (Table 1).

Characterization of Mycoplasms bovis: Samples were collected from dying young cattles after dissection. Lungs which showed major fibrinous necrotizing and suppurative lesions, were cut in a sterile manner, kept at around $4{ }^{\circ} \mathrm{C}$ and transported to the lab within a few hours and stored at $-20^{\circ} \mathrm{C}$. When the present study was undertaken, lung tissue scraps were obtained using an animal tissue sampler (China patent application number: 201120108302.2). After treatment by a Bullet Blender ${ }^{\circledR}$ homogenizer (Next Advance inc., USA) with $1.5 \mathrm{~mL}$ polypropylene tubes, the supernatant was divided into labeled aliquots, serially diluted and inoculated in fresh liquid media and cultivated at $37^{\circ} \mathrm{C}$ until the cell density was approximate $10^{5}$ cells $\mathrm{mL}^{-1}$.

At each day interval, Color-Change Units (CCU) which are directly related to the titre of viable mycoplasmas were determined as described previously (Ueno et al., 2008).

The colony morphology was investigated by microscopy. A nest or duplex PCR was carried out using a GeneAmp ${ }^{\circledast}$ PCR System 9700 (Applied Biosystems, USA) for verification.

The nested PCR was followed according to Pinnow et al. (2001) using outside primers (PpMB920-1 and PpMB920-2) and inside primers (PpSM5-1 and PpSM5-2). After 35 cycles of $94^{\circ} \mathrm{C}$ for $30 \mathrm{sec}, 48^{\circ} \mathrm{C}$ for $60 \mathrm{sec}$ and $72^{\circ} \mathrm{C}$ for $120 \mathrm{sec}$, the outside reaction product was diluted 1:100. The inside reaction was carried out under the same conditions except the annealing temperature of $54^{\circ} \mathrm{C}$, a 442 bp DNA fragment was specifically amplified.

A duplex-PCR assay (Liu et al., 2010) was adapted for the differential detection of $M$. bovis and M. mycoides
Table 2: Determination of growth of $M$ bovis in $400 \mu \mathrm{L}$ fresh medium in $1.5 \mathrm{~mL}$ eppendorf tube using Color-Change Units (CCU) Time (h)

\begin{tabular}{lllllllllll}
$\mathrm{CCU}$ & 24 & 48 & 72 & 96 & 120 & 144 & 168 & 192 & 216 & 240 \\
\hline $10^{5}$ & - & + & & & & & & & & \\
$10^{4}$ & - & - & + & & & & & & & \\
$10^{3}$ & - & - & - & + & & & & & & \\
$10^{2}$ & - & - & - & & + & & & & & \\
$10^{1}$ & - & - & - & - & - & - & + & & & \\
$10^{\circ}$ & - & - & - & - & - & - & - & - & - & - \\
\hline
\end{tabular}

CCU was determined over a period of $240 \mathrm{~h}$ from cultures inoculated with the approximate number of bacteria shown $(100 \mu \mathrm{L}$ aliquot of $M$ bovis inoculum with a 10 fold serial dilution of initial concentration of $8.6 \times 10^{5}$ CFU $\mathrm{mL}^{-1}$ ). + : Indicates a change in the color of the medium from red to yellow; -: Indicates no change in medium color

ssp. mycoides $\mathrm{SC}(\mathrm{MmmSC})$ using primers specific to M. bovis and $\mathrm{MmmSC}$, respectively. A 528 bp DNA fragment was specifically amplified from the $M$. bovis and a $270 \mathrm{bp}$ fragment from the $\mathrm{MmmSC}$ type strain PG1. The cycling conditions were an initial denaturing step at $94^{\circ} \mathrm{C}$ for $5 \mathrm{~min}$ followed by 35 cycles of $94^{\circ} \mathrm{C}$ for $45 \mathrm{sec}, 52^{\circ} \mathrm{C}$ for $40 \mathrm{sec}$ and $72^{\circ} \mathrm{C}$ for $60 \mathrm{sec}$.

Total $10 \mu \mathrm{L}$ aliquots of the PCR product were separated by electrophoresis in a $1 \%(\mathrm{w} / \mathrm{v})$ agarose gel. The gel was then stained with ethidium bromide $\left(0.5 \mu \mathrm{g} \mathrm{mL}^{-1}\right)$ for photography. Positive bands were cut and verified via sequencing by Invitrogen Corporation Shanghai Representative Office (Table 2).

\section{RESULTS AND DISCUSSION}

A contagious respiratory disease of cattle occurred in a farm in Guizhou Province of China in 2010. The main symptoms of this disease were coughing and high fever which led to the death of 4 out of 35 infected cattle. The pathogenic samples were collected from young calf lungs with a patented animal tissue sampler. As shown in Fig. 1, a positive sample was confirmed by nest and duplex PCR amplification. Targeting lipoprotein P80 DNA 504 bp fragment using pMB81-1 as a sequencing primer demonstrated 95 and $99 \%$ homology with $M$. bovis type strain PG45 clone MU clone A2 and M. bovis Hubei-1. When the sera were tested for antibody against $M$. bovis using a commercial kit (Biovet), positive results were obtained from all 35 samples.

$M$. bovis suspension was divided into aliquots inoculated in fresh liquid medium in $10 \mathrm{~mL}$ tubes $(10 \times 5)$ or $1.5 \mathrm{~mL}$ eppendorf tubes and incubated at $37^{\circ} \mathrm{C}$ with or without $5 \% \mathrm{CO}_{2}$. As is shown in Fig. 2, a change in the color of the medium from red to yellow increases when the initial medium volume decreases (i.e., the upper air space increases). The $400 \mu \mathrm{L}$ fresh medium plus $100 \mu \mathrm{L}$ inoculum was chosen as the optimum with regard to a comparative test of the liquid cultural method for sufficient M. bovis 


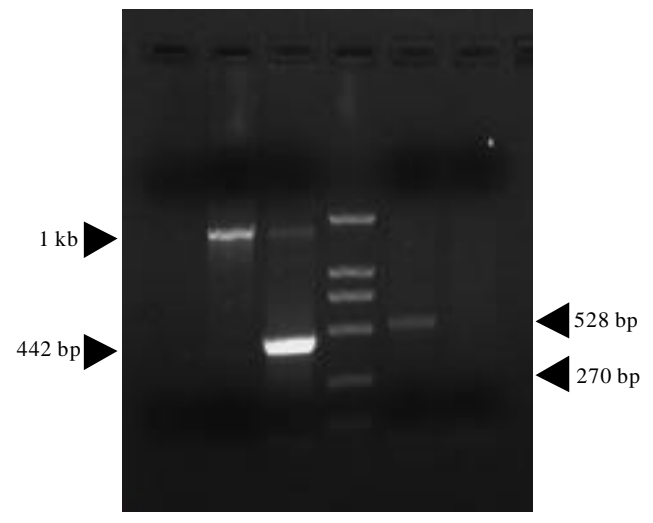

Fig. 1: A PCR-confirmed $M$. bovis positive sample. Lane 1: nested PCR 1000 bp product using outer primers; Lane 2: nested PCR 442 bp product using inner primers; Lane 3: ML2000 Marker (TaKaLa); Lane 4: 528 bp DNA fragment specific to $M$. bovis, 270 bp DNA fragment specific to MmmSC type strain PG1 was nagtive

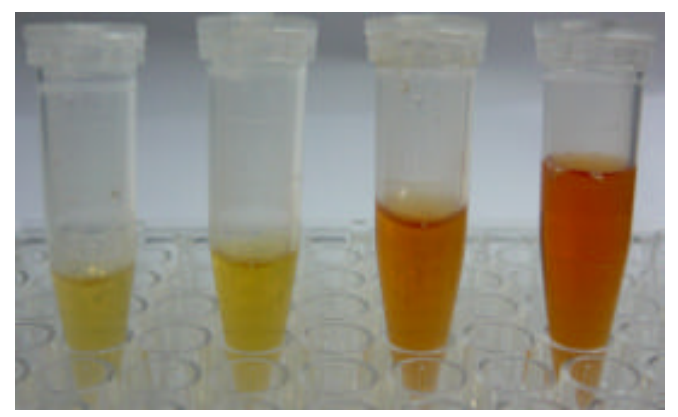

Fig. 2: Effect of the upper air space on the change in the color of the medium. The $200,400,600$ or $800 \mu \mathrm{L}$ fresh medium (from left to right) plus $100 \mu \mathrm{L}$ inoculum $\left(8.6 \times 10^{5} \mathrm{CFU} \mathrm{mL}^{-1}\right)$ in each eppendorf tube was incubated at $37^{\circ} \mathrm{C}$ for 4 days

reproduction. The most suggestive evidence in growth behavior by the two broth cultural methods was obtained when their growth dynamics were examined by CCU enumeration.

As expected, both methods showed evident growth between starting inocula of $10^{5}$ and $10^{1}$, for at least 10 starting organisms were required to establish growth in broth culture (Table 1 and 2).

When cultured in an open dish (Fig. 3a) at $37^{\circ} \mathrm{C}$ with $5 \% \mathrm{CO}_{2}, M$. bovis had a typical colony formation commonly described as fried egg due to the opaque granular central zone of growth penetrating the agar surrounded by a flat translucent peripheral zone on the surface while cultured in a sealed dish, colony formation changed a bit with a smaller opaque granular central zone

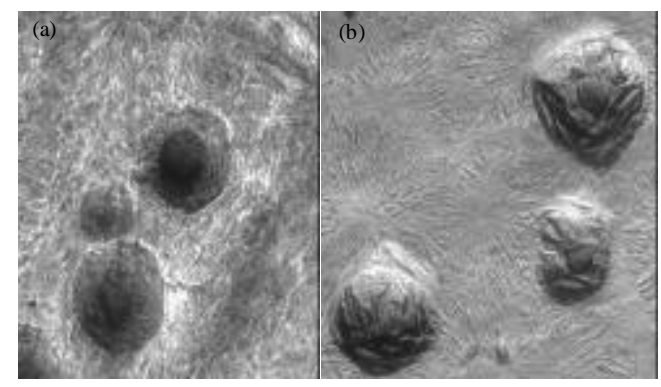

Fig. 3: Micrograph of $M$. bovis colonies (40x). a) Colonies in an open dish and b) a sealed dish were photographed by using an inverted microscope (eye piece of WH1Ox-H22 and object lens of UPlanF1 4x/0.13 PHL, Olympus IX70) at day 8th post-inoculation

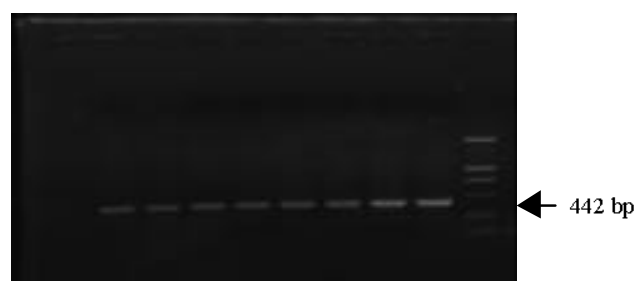

Fig. 4: Nested PCR-amplified $M$. bovis 442 bp products from 10 fold serially diluted inoculated cultures. Lane 1: Negative control (fresh liquid medium); Lane 2: $8.6 \times 10^{-1}$; Lane $3: 8.6 \times 10^{0}$; Lane 4: $8.6 \times 10^{1}$; Lane 5: $8.6 \times 10^{2}$; Lane 6: $8.6 \times 10^{3}$; Lane $7: 8.6 \times 10^{4}$; Lane 8: $4.3 \times 10^{4}$; Lane 9: $8.6 \times 10^{5}$; Lane 10: Positive control (frozen preserved $M$. bovis broth) and Lane 11: ML2000 Marker (TaKaLa)

and more irregular peripheral zone (Fig. 3b). Both methods of plating were very convenient for $M$. bovis culture because the colonies could be distinguished when viewed by a low-power microscope and could be easily applied for further culture and investigation. As shown in Fig. 4, a nested PCR was used to validate the starting inocula from $8.6 \times 10^{0}$ to $8.6 \times 10^{5} \mathrm{CFU} \mathrm{mL}^{-1}$, the amplified $442 \mathrm{bp}$ M. bovis DNA products showed that initial $100 \mu \mathrm{L}$ inocula aliquot of $8.6 \times 10^{1} \mathrm{CFU} \mathrm{mL}^{-1} M$. bovis suspension into $400 \mu \mathrm{L}$ fresh medium in $1.5 \mathrm{~mL}$ eppendorf tubes should be detected after incubation at $37^{\circ} \mathrm{C}$ for 4 days, i.e., 3 days earlier when compared with CCU enumeration.

There are several circumstances under which the use of culture and microscopy detection, coupling with PCR identification seems to offer some advantages. One application is the direct examination of clinical material. The method requires some experience and also to some 
extent, special optical equipment. This will certainly limit the number of laboratories in which cultural and microscopic examination can be used as a diagnostic tool for detection of M. bovis. However, with the fresh medium easily prepared and dispatched into eppendorf tubes, the initial liquid cultural procedure could perhaps provide possibility for rapid diagnosis of the disease by ColorChange Units (CCU) enumeration. Further solid culture procedure with the Petri dish sealed by Parafilm ${ }^{\circledR} \mathrm{M}$ provides a simple way to characterize $M$. bovis colonies. It is easy to generate microaerobic conditions without a $\mathrm{CO}_{2}$ incubator, to prevent further drying of the medium and to prevent contaminating from fungi or bacteria after long time incubation.

\section{CONCLUSION}

The results showed an improved method for the detection of $M$. bovis using an eppendorf tube and a sealed plate which can be easily handled and can generate microaerobic conditions suitable to growth of $M$. bovis. The combination of the two cultural methods and following Color-Change Units (CCU) enumeration, colony morphology or PCR assay shows an effective procedure to detect $M$. bovis which has the potential for easy diagnostic applications.

\section{ACKNOWLEDGEMENT}

This research was supported by Guizhou Provincial Fund for Science and technology (Grant No.: 20102114).

\section{REFERENCES}

Bahador, A., H. Etemadi, B. Kazemi, M. Hajabdolbaghi and M. Heidari et al., 2006. Novel ESAT-1081 multiplex PCR for direct detection and identification of BCG strains from other members of $m$. tuberculosis complex. Pak. J. Biol. Sci., 9: 1572-1576.

Ghadersohi, A., R.J. Coelen and R.G. Hirst, 1997. Development of a specific DNA probe and PCR for the detection of Mycoplasma bovis. Vet. Microbiol., 56: 87-98.

Gourlay, R.N. and S.B. Houghton, 1985. Experimental pneumonia in conventionally reared and gnotobiotic calves by dual infection with Mycoplasma bovis and Pasteurella haemolytica. Res. Vet. Sci., 38: 377-382.
Hale, H.H., C.F. Helmboldt, W.N. Plastridge and E.F. Stula, 1962. Bovine mastitis caused by a Mycoplasma species. Cornell Vet., 52: 582-591.

Hayflick, L., 1965. Tissue cultures and Mycoplasma. Tex. Rep. Biol. Med., 23: 285-303.

Hotzel, H., K. Sachse and H. Pfutzner, 1996. Rapid detection of Mycoplasma bovis in milk samples and nasal swabs using the polymerase chain reaction. J. Applied Bacteriol., 80: 505-510.

Jasper, D.E., 1981. Bovine mycoplasmal mastitis. Adv. Vet. Sci. Comp. Med., 25: 121-159.

Kumar, A., A.K. Verma, N.K. Gangwar and A. Rahal, 2012. Isolation, characterization and antibiogram of mycoplasma bovis in sheep pneumonia. Asian J. Anim. Vet. Adv., $7:$ 149-157.

Li, F., Y. Li, W. Jiang, Z. Wang and J. Li, 2005. Cloning and functional analysis of the sequences flanking mini-Tn5 in the magnetosomes deleted mutant NM4 of Magnetospirillum gryphiswaldense MSR-1. Sci. China C Life Sci., 48: 574-584.

Liu, Y., Y. Li, H. Dong, M.J. Zhang, H.F. Jiang, W. Chen and J.Q. Xin, 2010. Establishment of a duplex-PCR assay for detection of Mycoplasma bovis. Chin. J. Prevent. Vet. Med., 32: 599-602.

Pinnow, C.C., J.A. Butler, K. Sachse, H. Hotzel, L.L. Timms and R.F. Rosenbusch, 2001. Detection of Mycoplasma bovis in preservative-treated field milk samples. J. Dairy Sci., 84: 1640-1645.

Rodriguez, F., D.G. Bryson, H.J. Ball and F. Forster, 1996. Pathological and immunohistochemical studies of natural and experimental Mycoplasma bovis pneumonia in calves. J. Comp. Pathol., 115: 151-162.

Sachse, K., H. Pfutzner, H. Hotzel, B. Demuth, M. Heller and E. Berthold, 1993. Comparison of various diagnostic methods for the detection of Mycoplasma bovis. Rev. Sci. Tech. Off. Int. Epiz., 12: 571-580.

Thomas, L.H., C.J. Howard, E.J. Stott and K.R. Parsons, 1986. Mycoplasma bovis infection in gnotobiotic calves and combined infection with respiratory syncytial virus. Vet. Pathol., 23: 571-578.

Ueno, P.M., J. Timenetsky, V.E. Centonze, J.J. Wewer and M. Cagle et al., 2008. Interaction of Mycoplasma genitalium with host cells: Evidence for nuclear localization. Microbiology, 154: 3033-3041. 